\title{
Plasma Renin Response to Treadmill Exercise in Secondary Hypertension Kidney Disease Patients
}

\author{
Hala Ezz Aldeen ${ }^{1}$, Mariam Elsayed Abd Elaal ${ }^{1}$, Wael Fouad Hussein Nassar ${ }^{2}$, \\ Khaled Kheder Alkhoudari ${ }^{3}$ \\ ${ }^{1}$ Department of Cardiopulmonary Disorders and Geriatrics, Faculty of Physical Therapy, Cairo University, Cairo, Egypt \\ ${ }^{2}$ Kidney Department, Elsahel Teaching Hospital, Cairo, Egypt \\ ${ }^{3}$ Kids Habilitation Center, Cairo, Egypt
}

Email address:

Khaledalkhodary13@hotmail.com (K. K. Alkhoudari)

\section{To cite this article:}

Hala Ezz Aldeen, Mariam Elsayed Abd Elaal, Wael Fouad Hussein Nassar, Khaled Kheder Alkhoudari. Plasma Renin Response to Treadmill Exercise in Secondary Hypertension Kidney Disease Patients. European Journal of Preventive Medicine. Vol. 5, No. 3, 2017 , pp. $33-38$. doi: $10.11648 /$ j.ejpm.20170503.11

Received: May 6, 2017; Accepted: May 16, 2017; Published: July 5, 2017

\begin{abstract}
Inhibition of renin activity has long been considered to be the logical step to interrupt the renin angiotensin aldosterone system which becomes the cornerstone to retard the progression of Chronic Kidney Disease. Currently, little is known about the impact of aerobic exercise on the plasma renin in chronic kidney disease patients. Aim of this study was to investigate the influence of aerobic exercise on plasma renin in the chronic kidney disease patients with secondary hypertension. Forty chronic kidney disease patients aged 40-55 years were randomly assigned to study group and control group. Study group performed moderate intensity aerobic exercise on an electronic treadmill for 30 minutes, 3 times per week, for 8 weeks. Control group received their medication only and no changes in their life style during the same trail period. The mean values for patients in groups A and B after the study were as following: For Plasma renin level $(0.82 \pm 0.214)$ and $(2.09 \pm$ $0.468)$ respectively, for systolic blood pressure $(152.1 \pm 4.86)$ and $(155.8 \pm 5.16) \mathrm{mmHg}$ respectively, for diastolic blood pressure $(95 \pm 3.81)$ and $(102.6 \pm 6.93) \mathrm{mmHg}$ respectively and for 6-minute walk test speed $(1.83 \pm 0.07)$ and $(1.68 \pm 0.06)$ $\mathrm{m} / \mathrm{s}$ respectively. There were significant differences between two groups in their Plasma renin level and blood pressure (systolic and diastolic) and 6-minute walk test speed after the study. It was concluded that moderate aerobic exercise resulted in improved kidney functions with chronic kidney disease in pre-dialysis patients as reducing plasma renin and improving the blood pressure with non-significant negative weak correlation between Plasma renin level and blood pressure and a significant moderate negative correlation between exercise improvement and plasma renin.
\end{abstract}

Keywords: Treadmill Exercise, Chronic Kidney Disease, Plasma Renin

\section{Introduction}

Chronic kidney disease is a progressive loss in renal function in months or years [1]. It recognized as a common condition associated with an increased risk of cardiovascular disease and chronic kidney failure [2]. Most of the cases of chronic kidney disease are slowly progressive to end stage renal failure, and hypertension is believed to be a major role in the pathogenesis [3]. Roughly $80 \%$ of the cases die, primarily of cardio vascular disease, before reaching the dialysis. Of those reached the dialysis, $45 \%$ would die of a cardiovascular cause [4].
Chronic kidney disease is the most common cause of secondary hypertension and mostly increased with the severity of chronic kidney disease [5]. Based on a national survey of representative sample of non-institutionalized adults in the United State of America, it is estimated that hypertension occurs in $23.3 \%$ of individuals without chronic kidney disease, and $35.8 \%$ of stage $1,48.1 \%$ of stage 2 , $59.9 \%$ of stage 3 , and $84.1 \%$ of stage $4-5$ chronic kidney disease patients [6]. Evidence from many clinical trials has showed the benefit of blood pressure control [7].

There is no specific treatment unequivocally shown to slow the worsening of chronic kidney disease [8] and the 
high costs of chronic kidney disease management has strongly stimulated the clinical applications of the nephroprotection concept, aimed at the early detection and subsequent prevention of progression of chronic kidney disease mainly through life style adjustment [9]. Moreover chronic kidney disease is associated with cachexia as a result of impaired protein synthesis and increased protein degradation especially affecting skeletal muscle will lead to gradual increase in muscle wasting [10].

Sodium and renin are the main factors in blood pressure control [11]. Renin is the key enzyme of the renin angiotensin aldosterone system [12]. Renin angiotensin aldosterone system amplifies sodium retention in the cortical collecting duct to restore extra cellular fluid volume and blood pressure towards normal [13]. In patients with hypertension plasma renin activity is inappropriately high for the level of $\mathrm{Na}+$ intake [11].

In non-diabetic kidney diseases, the information for the benefits of renin angiotensin aldosterone system inhibition on progression of chronic kidney disease is strongest in the patients with proteinuria $41000 \mathrm{mg}$ /day according to a recent meta-analysis. The African American study of kidney disease and hypertension trial confirmed this in African Americans patients with hypertensive nephropathy [14]. Also reduced body fat mass may reduce plasma renin activity suggesting a finding with therapeutic implications [15]. Further, an inverse relationship between plasma renin activity and levels of physical activity has been demonstrated in healthy mildly hypertensive individuals and plasma renin activity and levels of physical fitness [16].

Moderate aerobic exercise training of both localized muscle groups and whole body exercise is associated with improvement in risk factors and disease [17]. Exercise significantly improves the arterial stiffness as result from improved endothelial function [11]. A recent study noted a significant improvement in estimated glomerular filtration rate following 12 weeks of center-based aerobic training in overweight male patients with chronic kidney disease [18]. Further, Aerobic exercise in non-dialysis subjects improved symptoms scores, sickness impact profiles and health related quality of life [19].

Exercise training is effective in combating muscle atrophy associated with chronic kidney disease through up regulation of protein synthesis, increasing muscle mitochondrial content, and reducing muscle catabolism [20]. The most serious risk of exercise in the chronic kidney disease population are those of cardiac origin, ranging from dysrhythmia to ischemia to sudden death [21] as such, a blood pressure measure of $\geq 185 / 110$ is a contraindication for undertaking exercise [22].

Plasma renin activity can be affected by a number of lifestyle factors, among which are acute and chronic physical exercises [23]. Aerobic exercise helps control blood pressure by acting on mechanisms of blood pressure regulation, such as plasma renin activity [24]. Therefore the purpose of this study was to investigate the influence of treadmill exercise on plasma renin in hypertensive kidney disease patients.

\section{Research Design and Methods}

\section{Subjects characteristics and general experimental design}

\subsection{Study Subjects}

Forty chronic kidney disease patients with secondary hypertension (14 women and 26 men) participated in the study their age ranged (40-55 years). All patients were hypertensive stage 2 as blood pressure systolic was $<185$ $\mathrm{mmHg}$ and diastolic was $<109 \mathrm{mmHg}$ and estimated glomerular filtration rate was (30-89) and free from respiratory, liver, metabolic and neurological disorders as chronic inflammatory orthopedic diseases, rheumatoid or chronic cardiac problems as heart failure and ischemic heart disease.

\subsection{Evaluated Parameters}

Plasma renin investigations and blood pressure measurement was carried at the beginning and at the end of the study as well as 6-minute walk test was used to follow up the functional capacity of the patients [25]. All measurements were recorded before the study for each subject in both groups and were repeated in the same manner at the end of the study period ( 8 weeks).

Ratings of perceived exertion are generally believed to be valid and reliable markers of physiological intensity during exercise [26] and are recommended to monitor exercise intensity [27]. Participants were randomly divided into two groups, Study group: treadmill exercise training and control group received medication only. The study procedures were carried out at Outpatient Clinic of the Faculty of Elsahel teaching hospital. All subjects were free to withdraw from the study at any time. All participants provided their informed consent after receiving a detailed explanation of the study. The data of all the forty participants were available for analysis. The detailed exercise protocol was as follows.

\subsection{Exercise Protocol}

For the entire session all patients had to adhere to identical exercise protocol. After an initial 5 minutes worming up phase performed on the treadmill at low load. The speed was increased until the patient reached moderate intensity (11-14 on Borg scale) then the subject walked at the obtained level of speed for 30 minutes and ended with 5 minutes cooling down as worming up [28].

\subsection{Statistical Analysis}

The collected data were statistically analyzed using paired t- test. The data were represented as: mean, standard deviation. Spearman correlation coefficient $\left(r^{2}\right)$ was used to find out the relationship between variables.

\section{Results}

Forty hypertensive chronic kidney disease patients were assigned randomly into two groups. 
Study group: 20 patients performed aerobic exercise for 8 weeks, 3 times a week plus medical treatment. As shown in table 1 their mean age, height, weight and body mass index were $(49.8 \pm 3.9)$ years, $(170.4 \pm 8.14) \mathrm{cm},(97.2 \pm 8.9) \mathrm{kg}$ and $(32.47 \pm 1.18) \mathrm{kg} / \mathrm{m}^{2}$ respectively.

Control group: 20 patients received medical treatment only. As shown in table 1 and their mean age, height, weight and body mass index were $(49.1 \pm 4.1)$ years, $(167.1 \pm 8.31)$ $\mathrm{cm},(92.3 \pm 8.5) \mathrm{kg}$., and $(32.63 \pm 1.21) \mathrm{kg} / \mathrm{m}^{2}$ respectively.

As shown in table 1: There was non-significant difference between two groups in their age, height, weight, and body mass index.

As shown in table 2 there were no significant differences between two groups in their Plasma renin level and blood pressure (systolic and diastolic) and 6-minute walk test speed before the study. However, there were significant differences between two groups in their Plasma renin level and blood pressure (systolic and diastolic) and 6-minute walk test speed after the study as shown in table 3 . In table 4 there was nonsignificant positive weak correlation between Plasma renin level and systolic blood pressure for study group and there was non-significant negative weak correlation between Plasma renin level and diastolic blood pressure. Moreover there was a significant moderate positive correlation between 6-minute walk test speed and systolic and diastolic blood pressure for study group after the study.

Table 1. General characteristics of patients in both groups.

\begin{tabular}{llllll}
\hline General characteristics & & Age (yrs) & Height $(\mathbf{c m})$ & Weight & BMI \\
\hline \multirow{2}{*}{ Study group } & Mean & 49.8 & 170.4 & 97.2 & 32.47 \\
& \pm SD & 3.9 & 8.14 & 8.9 & 1.18 \\
\multirow{2}{*}{ Control group } & Mean & 49.1 & 167.1 & 92.3 & 32.63 \\
& \pm SD & 4.1 & 8.31 & 8.5 & 1.21 \\
\multirow{2}{*}{ Comparison } & t-value & 0.551 & 1.287 & 1.766 & -0.422 \\
& P-value & 0.585 & 0.206 & 0.085 & 0.676 \\
\hline
\end{tabular}

BMI, body mass index; Level of significance at $\mathrm{P}<0.05$

Table 2. Pre study mean values of measured parameters for both groups.

\begin{tabular}{|c|c|c|c|c|c|}
\hline \multirow{2}{*}{ Items } & & \multirow{2}{*}{ Plasma renin level } & \multicolumn{2}{|c|}{ Blood pressure } & \multirow{2}{*}{$\begin{array}{l}\text { 6-minute walk } \\
\text { test }\end{array}$} \\
\hline & & & Systolic & Diastolic & \\
\hline \multirow[t]{2}{*}{ Study group } & Mean & 2.43 & 156.2 & 101.1 & 1.69 \\
\hline & $\pm \mathrm{SD}$ & 0.37 & 3.67 & 4.78 & 0.013 \\
\hline \multirow{2}{*}{ Control group } & Mean & 2.38 & 154.5 & 100.5 & 1.70 \\
\hline & $\pm \mathrm{SD}$ & 0.37 & 5.89 & 7.3 & 0.024 \\
\hline Comparison & t-value & 0.421 & 0.307 & 1.004 & 1.638 \\
\hline
\end{tabular}

SD: standard deviation, P: probability

Table 3. Post study mean values of measured parameters for both groups.

\begin{tabular}{llllll}
\hline \multirow{2}{*}{ Items } & \multirow{2}{*}{ Plasma renin level } & Blood pressure & 6-minute walk \\
\cline { 5 - 6 } & & & Systolic & Diastolic & test \\
\hline \multirow{2}{*}{ Study group } & Mean & 0.82 & 152.1 & 95 & 1.83 \\
\% of improvement & $\pm \mathrm{SD}$ & 0.214 & 4.86 & 3.81 & 0.036 \\
\multirow{2}{*}{ Control group } & & $196 \%$ & $2.62 \%$ & $6.03 \%$ & $8.28 \%$ \\
\multirow{2}{*}{ \% of improvement } & Mean & 2.09 & 155.8 & 102.6 & 1.68 \\
Comparison & $\pm \mathrm{SD}$ & 0.468 & 5.16 & 6.93 & 0.025 \\
& & $12.18 \%$ & $-0.84 \%$ & $-2.08 \%$ & $-1.19 \%$ \\
& t-value & -11.017 & -2.33 & -4.27 & 15.305 \\
\end{tabular}

SD: standard deviation, P: probability

Table 4. Correlation between blood pressure, 6-MWT speed and plasma renin for study group.

\begin{tabular}{llll}
\hline \multirow{2}{*}{ Items } & \multirow{2}{*}{ Plasma renin level } & 6-minute walk \\
\cline { 3 - 4 } Systolic blood pressure & $\mathrm{r}^{2}$ & 0.008 & test \\
& $\mathrm{p}$-value & 0.973 & 0.528 \\
\multirow{2}{*}{ Diastolic blood pressure } & $\mathrm{r}^{2}$ & -0.361 & 0.016 \\
& $\mathrm{p}$-value & 0.118 & 0.425 \\
\hline
\end{tabular}

r2: Spearman correlation coefficient, P: probability 


\section{Discussion}

This study investigated the effect of moderate aerobic exercise on plasma renin in chronic kidney disease with secondary hypertension stage $(2,3)$. The aerobic exercise was performed using a motorized treadmill.

Forty chronic kidney disease patients with secondary hypertension (14 women and 26 men) participated in the study their age range (40-55 years). All patients were hypertensive (stage 2) and estimating glomerular filtration rate was (30-89) and free from respiratory, liver, metabolic and neurological disorders as chronic inflammatory orthopedic diseases, rheumatoid or chronic cardiac problems as heart failure and ischemic heart disease.

The study included two groups of subjects, Study group with twenty patients with chronic kidney disease stages 2 and 3 on medical treatment were performed moderate intensity aerobic exercise on an electronic treadmill for 30 minutes, 3 times per week, for 8 weeks. Control group with twenty patients with chronic kidney disease with secondary hypertension received their medication only with no changes in their life style during the same trail period.

All the participants didn't receive any physical therapy program before participated in the study and received a through explanation of the procedures and duration before starting the study.

Inactivity is associated with the development of major chronic kidney disease precursors including albuminuria, reduced glomerular filtration rate and diabetes [29]. The benefits of exercise training of the current study were generalized on many aspects firstly after adherence of patients to the current study they have been encouraged and motivated to participate in regular exercise program as they physically touched the benefits of exercises in the form of overall improvement in the performance of ordinary activities of daily living which may be affected from the disease. This functional improvement occurred through increasing circulatory capacity and aerobic fitness that assist patients to maintain normal activities. Secondly the psychological status of the subject has been improved resulting in more activities. Finally in sequence from all of the above the quality of life and well-being of patient have been enhanced in great aspect. Increasing physical activity is therefore an essential aspect of disease prevention and management in chronic kidney disease patients at least 3 days a week for 30 minutes [30].

Most nephrologists' belief that the chronic kidney disease patients are not able to perform exercise because it is impossible for them to increase their aerobic capacity and the strong catabolic force of uremia prevent exercise induced effects on muscle endurance or strength [31]. Recent researches showed that exercise capacity modify peak VO2, potential of exercise as an intervention to improve survival is suggested because patients with elevated plasma renin levels $(>1.7 \mathrm{ng} / \mathrm{ml} / \mathrm{hr}$ ) had a tendency to decrease their Blood Pressure somewhat less than those with normal plasma renin levels (11 vs. $17 \mathrm{~mm} \mathrm{Hg}$ systolic, 10 vs. $13 \mathrm{mmHg}$ diastolic, respectively) [32]. In this way, exercise should be an essential part of the management plan for chronic kidney disease patients [33]. Moreover long-term exercise training improves physical impairment, arterial stiffness and healthrelated quality of life in pre-dialysis chronic kidney disease patients [34].

A study by Kiyonaga $\mathrm{A}$, et al have reported that persons with elevated plasma renin levels decreased their blood pressure with exercise training, whereas those with normal renin levels did not change their blood pressure [35]. The current study came in agreement with Jennings GA, et al they suggested that reduction in plasma renin activity probably contributed to the falls in total peripheral resistance and blood pressure during increased activity [36]. One of the recent studies that support these results was applied by Waib $\mathrm{PH}$, et al. They found that decreased activity of the autonomic nervous system lower plasma renin activity and reduction in insulin resistance are suggested mechanisms that underlie training-induced reductions in blood pressure. Changes in plasma aldosterone and cortisol could also be involved in blood pressure regulation during aerobic training. Neuro-hormonal and vascular adaptations are also potential mechanisms that could explain blood pressure lowering effect of endurance training in hypertension [37]. The results of the current study were confirmed by Aoike DT et al. The decrease in blood pressure due to mild/moderate aerobic exercise has been well established both in normotensive and hypertensive individuals as well as in chronic kidney disease patients. Aerobic training lowers blood pressure by reducing peripheral vascular resistance due to the improvement of endothelium-mediated vasodilatation, attenuation of increased sympathetic nervous system activity and vascular remodeling [38]. On the other hand, The results of current study not went will with Headley $\mathrm{S}$ et al. Exercise had no effect upon either resting or ambulatory blood pressure in chronic kidney disease patients because blood pressure of the patients was already very well controlled by antihypertensive medications [39].

All these findings indicated that moderate aerobic exercise using a motorized treadmill improved blood pressure and reduced plasma renin in chronic kidney disease patients with secondary hypertension which further supporting that moderate aerobic exercise can be recommended in plane of treatment. In addition, study participants demonstrated a high level of compliance with exercise program proposed suggest that a high level of adherence in a chosen aerobic exercise activity.

The correlation of increased mortality with low physical activity, low muscle mass and reduced physical functioning provides a clear rationale for exercise in chronic kidney disease patients. It should be emphasized that most frail and in capacitated patients are probably those most in need of physical rehabilitation as a part of their clinical care. 


\section{Conclusion}

Chronic kidney disease is associated with considerable decline in kidney function that has profound effects on patient's effective functioning in everyday life. Physical exercise might be effective in improving kidney functions. Moderate aerobic exercise resulted in improved kidney functions with chronic kidney disease in pre-dialysis patients as reducing plasma renin and improving the blood pressure with non-significant negative weak correlation between Plasma renin level and blood pressure and a significant moderate positive correlation between exercise improvement and systolic and diastolic blood pressure.

\section{References}

[1] Levey AS, Coresh J, Balk E, Kausz AT, Levin A, Steffes MW, Hogg RJ, Perrone RD, Lau J, Eknoyan G. National Kidney Foundation practice guidelines for chronic kidney disease: evaluation, classification, and stratification. Annals of internal medicine. 2003 Jul 15; 139 (2): 137-47.

[2] Thomas R, Kanso A, Sedor JR. Chronic kidney disease and its complications. Primary care: Clinics in office practice. 2008 Jun 30; 35 (2): 329-44.

[3] Kalra PA. Renal specific secondary hypertension, J Ren Care 2007 Jan-Mar; 33 (1): 4-10.

[4] Papadakis MA, McPhee SJ, Rabow MW. Current medical diagnosis \& treatment 2013. McGraw-Hill Medical; 2013.

[5] Go AS, Chertow GM, Fan D, McCulloch CE, Hsu CY. Chronic kidney disease and the risks of death, cardiovascular events, and hospitalization. New England Journal of Medicine. 2004 Sep 23; 351 (13): 1296-305.

[6] Collins AJ, Foley RN, Chavers B, Gilbertson D, Herzog C, Johansen K, Kasiske B, Kutner N, Liu J, Peter WS, Guo H. US Renal Data System 2011 Annual Data Report. American Journal of Kidney Diseases. 2012 Jan 1; 59 (1): A7.

[7] Tedla FM, Brar A, Browne R, Brown C. Hypertension in chronic kidney disease: navigating the evidence. International journal of hypertension. 2011 May 24; 2011.

[8] Stevens LA, Levey AS. Current status and future perspectives for CKD testing. American Journal of Kidney Diseases. 2009 Mar 31; 53 (3): S17-26.

[9] Grassmann A, Gioberge S, Moeller S, Brown G. ESRD patients in 2004: global overview of patient numbers, treatment modalities and associated trends. Nephrology Dialysis Transplantation. 2005 Dec 1; 20 (12): 2587-93.

[10] Kosmadakis GC, Bevington A, Smith AC, Clapp EL, Viana JL, Bishop NC, Feehally J. Physical exercise in patients with severe kidney disease. Nephron Clinical Practice. 2010 Feb 19; 115 (1): c7-16.

[11] Brown MJ. Renin: friend or foe?. Heart. 2007 Sep 1; 93 (9): 1026-33.

[12] Castrop H, Höcherl K, Kurtz A, Schweda F, Todorov V, Wagner C. Physiology of kidney renin. Physiological Reviews. 2010 Apr 1; 90 (2): 607-73.
[13] Walker BR, Colledge NR. Davidson's principles and practice of medicine. Elsevier Health Sciences; 2013 Dec 6.

[14] Turner JM, Bauer C, Abramowitz MK, Melamed ML, Hostetter TH. Treatment of chronic kidney disease. Kidney international. $2012 \mathrm{Feb} 2 ; 81$ (4): 351-62.

[15] Engeli S, Böhnke J, Gorzelniak K, Janke J, Schling P, Bader M, Luft FC, Sharma AM. Weight loss and the reninangiotensin-aldosterone system. Hypertension. 2005 Mar 1; 45 (3): 356-62.

[16] Goessler K, Polito M, Cornelissen VA. Effect of exercise training on the renin-angiotensin-aldosterone system in healthy individuals: a systematic review and meta-analysis. Hypertension Research. 2015 Sep 24.

[17] Hambrecht R, Wolf A, Gielen S, Linke A, Hofer J, Erbs S, Schoene N, Schuler G. Effect of exercise on coronary endothelial function in patients with coronary artery disease. New England Journal of Medicine. 2000 Feb 17; 342 (7): 45460 .

[18] Baria F, Kamimura MA, Aoike DT, Ammirati A, Rocha ML, de Mello MT, Cuppari L. Randomized controlled trial to evaluate the impact of aerobic exercise on visceral fat in overweight chronic kidney disease patients. Nephrology Dialysis Transplantation. 2014 Apr 1; 29 (4): 857-64.

[19] Moinuddin I, Leehey DJ. A comparison of aerobic exercise and resistance training in patients with and without chronic kidney disease. Advances in chronic kidney disease. 2008 Jan 31; 15 (1): 83-96.

[20] Watson EL, Kosmadakis GC, Smith AC, Viana JL, Brown JR, Molyneux K, Pawluczyk IZ, Mulheran M, Bishop NC, Shirreffs S, Maughan RJ. Combined walking exercise and alkali therapy in patients with CKD4-5 regulates intramuscular free amino acid pools and ubiquitin E3 ligase expression. European journal of applied physiology. 2013 Aug $1 ; 113(8): 2111-24$.

[21] Johansen KL. Exercise and chronic kidney disease. Sports medicine. 2005 Jun 1; 35 (6): 485-99.

[22] Wilkinson TJ, Shur NF, Smith AC. "Exercise as medicine" in chronic kidney disease. Scandinavian journal of medicine \& science in sports. 2016 Aug 1; 26 (8): 985-8.

[23] Patlar S. Effect of acute and chronic submaximal exercise on plasma renin and aldosterone levels in football players. Isokinetics and exercise science. 2011; 19 (3): 227-30.

[24] Martinelli B, Barrile SR, Arca EA, Franco RJ, Martin LC. Effect of aerobic exercise on plasma renin in overweight patients with hypertension. Arquivos brasileiros de cardiologia. $2010 \mathrm{Jul} ; 95$ (1): 91-8.

[25] Zainuldin R, Mackey MG, Alison JA. Prescription of walking exercise intensity from the 6-minute walk test in people with chronic obstructive pulmonary disease. Journal of cardiopulmonary rehabilitation and prevention. 2015 Jan 1; 35 (1): 65-9.

[26] Eng JJ, Chu KS, Dawson AS, Kim CM, Hepburn KE. Functional walk tests in individuals with stroke. Stroke. 2002 Mar 1; 33 (3): 756-61.

[27] American College of Sports Medicine. ACSM's guidelines for exercise testing and prescription. Lippincott Williams \& Wilkins; 2013 Mar 4. 
[28] Løppenthin K, Esbensen BA, Jennum P, Østergaard M, Christensen JF, Thomsen T, Bech JS, Midtgaard J. Effect of intermittent aerobic exercise on sleep quality and sleep disturbances in patients with rheumatoid arthritis - design of a randomized controlled trial. BMC Musculoskelet Disord. 2014 Feb 21; 15: 49. doi: 10.1186/1471-2474-15-49.

[29] Robinson-Cohen C, Katz R, Mozaffarian D, Dalrymple LS, De Boer I, Sarnak M, Shlipak M, Siscovick D, Kestenbaum B. Physical activity and rapid decline in kidney function among older adults. Archives of internal medicine. 2009 Dec 14; 169 (22): 2116-23.

[30] Kirkman DL, Lennon-Edwards S, Edwards DG. Exercise for Chronic Kidney Disease. Journal of renal nutrition: the official journal of the Council on Renal Nutrition of the National Kidney Foundation. 2014 Nov; 24 (6): e51.

[31] Rahmy AF, Afifi WM, Ghorab AA, Mostafa HA. Effect of moderate aerobic exercises on kidney function and lipid profile in chronic kidney disease patients. Journal of The Egyptian Society of Nephrology and Transplantation. 2016 Jul 1; 16 (3): 97.

[32] Hagberg JM, Montain SJ, Martin WH, Ehsani AA. Effect of exercise training in 60-to 69-year-old persons with essential hypertension. The American journal of cardiology. 1989 Aug 1; 64 (5): 348-53.

[33] Morishita Y, Nagata D. Strategies to improve physical activity by exercise training in patients with chronic kidney disease. International journal of nephrology and renovascular disease. 2015; 9: 19.
[34] Mustata S, Groeneveld S, Davidson W, Ford G, Kiland K, Manns B. Effects of exercise training on physical impairment, arterial stiffness and health-related quality of life in patients with chronic kidney disease: a pilot study. International urology and nephrology. 2011 Dec 1; 43 (4): 1133-41.

[35] Kiyonaga A, Arakawa K, Tanaka H, Shindo M. Blood pressure and hormonal responses to aerobic exercise. Hypertension. 1985 Jan 1; 7 (1): 125-31.

[36] Jennings GA, Nelson L, Nestel PA, Esler M, Korner P, Burton $\mathrm{D}$, Bazelmans J. The effects of changes in physical activity on major cardiovascular risk factors, hemodynamics, sympathetic function, and glucose utilization in man: a controlled study of four levels of activity. Circulation. 1986 Jan 1; 73 (1): 30-40.

[37] Waib PH, Gonçalves MI, Barrile SR. Improvements in insulin sensitivity and muscle blood flow in aerobic-trained overweight-obese hypertensive patients are not associated with ambulatory blood pressure. The Journal of Clinical Hypertension. 2011 Feb 1; 13 (2): 89-96.

[38] Aoike DT, Baria F, Rocha ML, Kamimura MA, Mello MT, Tufik S, Ammirati A, Cuppari L. Impact of training at ventilatory threshold on cardiopulmonary and functional capacity in overweight patients with chronic kidney disease. Jornal Brasileiro de Nefrologia. 2012 Jun; 34 (2): 139-47.

[39] Headley S, Germain M, Milch C, Pescatello L, Coughlin MA, Nindl BC, Cornelius A, Sullivan S, Gregory S, Wood R. Exercise training improves $\mathrm{HR}$ responses and $\mathrm{VO} 2$ peak in predialysis kidney patients. Medicine and science in sports and exercise. 2012 Dec; 44 (12): 2392-9. 